\title{
Weight Analysis of QoS Based Cloud Evaluation Index System
}

\author{
Cong Cheng \\ Information Center, Beijing Polytechnic College, Beijing, China \\ chengc@bgy.org.cn
}

\begin{abstract}
This thesis aims to analyze and study construction of public cloud evaluation index system and its weight. As specified, ANP Model is to be used for creative construction of two-level cloud service quality evaluation index system in combination with features of cloud computation; whereas Super Decision Software is to be used for computation of weight of primary and secondary indexes and sequencing of their importance in an attempt to put forward a novel conception on evaluation of cloud service quality.
\end{abstract}

Keywords-cloud service;QoS; Service Quality; Index system

\section{INTRODUCTION}

Currently, public cloud service is still at the initial stage in China despite of its rapid development. As a novel business mode for provisions of IT resources, governmental agencies, enterprises and individual users are concerned about safety and quality of public cloud service in different degrees. According to the survey by China Academy of Telecommunication Research of MIIT, more than 50\% users are concerned about safety, reliability, service quality, etc. of cloud service. This has affected further promotion and deepening of public cloud application to some extent.

\section{Status Quo of Cloud SERVICE QuAlity EVALUATION INDEX SYSTEM}

To promote well regulated competition and rapid development of cloud service market, and provide users with a safe and reliable purchase guarantee, it is essential to evaluate public cloud service quality. However, despite of the fact Service Level Agreement (SLA) has been concluded between cloud provider and consumers concerning the three cloud services represented by IaaS, PaaS and SaaS, there is in lack of a uniform, systematic and scientific selection and survey of SLA parameters. Construction of QoS based (Quality of Service) cloud evaluation index and weight analysis of the index system are favorable for selection of excellent and inexpensive service providers as per users' requirements, which can also serve as an effective basis for unification of SLA.

Nevertheless, relevant studies on cloud service quality evaluation index system are so limited in the industry. Even if individual literatures propose cloud service quality evaluation functions, some of them directly and mechanically apply well-established Web service quality evaluation model; whereas others are only limited to a certain cloud service index for quantitative analysis, which are in lack of qualitative study. For this reason, a scientific research topic titled "Study of Cloud Service Quality Index
System" was established for the purpose of thesis in 2015. The topic group consists of experienced specialized mathematic teachers. The topic is expected to construct optimal cloud service quality evaluation index system with analytic network process (ANP), and use Super Decision Software to analyze weight of primary and secondary indexes based on a mass of survey and studies as well as public cloud service.

\section{EVALUATION INDEX CONSTRUCTION AND DESIGN PRINCIPLES}

\section{A. Evaluation Index Construction Methods}

Analysis of cloud service quality evaluation index is a decision making issue of multi attributes. The most classical decision making analysis methods of multi attributes include simple linear weighting method, technique for order preference by similarity to an ideal solution (TOPSIS), analytic hierarchy process (AHP) and analytic network process (ANP). Such decision making analysis methods have different applications. Simple linear weight method is mainly applicable to mutual independence of each evaluation index; whereas ideal point method mainly aims at sequencing based on "ideal solution" and "negative ideal solution" for decision making issues with multi objectives. The two methods are basically not involved with hierarchical relationship between each evaluation index. AHP requires no influencing relationship between each element of index at each hierarchy. ANP is provided with some major features of AHP, especially at the control hierarchy. It basically follows hierarchical structure of AHP in dealing with various criteria. However, as it permits mutual reliance among elements at the network layer, all elements are not limited to the superincumbent subordination. What is based on each cloud service quality index is network structure form other than hierarchical structure. Obviously, it is applicable to use ANP method for weight analysis of cloud evaluation index system in this thesis.

Simply speaking, all elements are divided into two parts according to ANP method: The first part is control layer, including problem target and decision making criteria; each decision making criterion is mutually independent without any influencing relationship, which is dominated by target elements. The second part is known as network layer as dominated by the control layer; there exists an influencing relationship among most of elements. 


\section{B. Index System Design Principles}

Cloud computation is expected to distribute computation results on numerous distributive computers in different regions other than local computers or remote servers; whereas operation of enterprise data center is similar to internet. As a result of it, enterprises can shift resources to required application for access to the computer and memory system as per demands.

Similar to evolution from traditional single generator mode to centralized power supply mode, cloud computation means that such IT resources as computation and memory are available for circulation as commodities. All users can take what they want as per respective demands at a low price in the same manner as gas, water and electricity. As different from water, electricity and gas, such resources are provided to users via internet.

IaaS, PaaS and SaaS are without exception provided with such features as low price, demands based service, high reliability, dynamic extensibility, universality, service virtualization and large-scale computation. Researchers in different fields have different definitions and classifications of cloud service quality due to varied focuses. Therefore, it is difficult to establish an absolutely universal service quality evaluation model. We hereby manage to construct cloud service evaluation index system (e.g. Table 1) by giving priority to cloud service features.

\section{INFLUENCING RELATIONSHIP BETWEEN EACH EVALUATION INDEX}

Questionnaire analysis was applied to "Importance of Cloud Service Quality Evaluation Index” during research.

There exists mutual influencing relationship between each secondary index for cloud service quality; however, such influencing relationship is not applicable to all secondary indexes. For this purpose, the topic group has interviewed numerous renowned experts in the industry, and referred to numerous literatures in an attempt to define influencing relationship between each secondary index on this basis (Table 2). Any array and row in the table refers to father node and sub-node respectively; father node is influenced by the sub-node. On this account, the most direct questionnaire method is not selected. This is mainly due to the fact that numerous specialized contents in questionnaire may affect the patience of interviewee and quality of reclaimed questionnaire to some extent.

\section{Weight SEQUenCing OF InDEXEs AT EACH LEVEL}

In view of mutual reliance and complicated feedback effect among secondary indexes, it will be complicated to compute weight of each index without software. Therefore, Super Decision Software was used by the topic group to perform such task.

To figure out index importance in an objective and scientific manner, approximately 40 questionnaires (namely survey of importance to cloud service quality evaluation indexes) have been designed and distributed according to this thesis. Most of participants of survey are CIO and network administrators. This aims to figure out importance of primary and secondary indexes. "Scale 1-9" as proposed by Saaty was used for scaling of importance to two evaluation indexes. In the scale, evaluation value 0 means "non influence between two indexes"; 1 refers to "equal importance of the two indexes"; 3 means "former factor is slightly important than the later"; 5 means "former factor is obviously more important than the later"; 7 means "former factor is significantly more important than the later"; 9 means "former factor is extremely more important than the later". Evaluation value 2, 4, 6 and 8 refers to intermediate value of two adjacent judgments.

TABLE I. DESCRIPTION OF EACH CLOUD SERVICE QUALITY EVALUATION INDEX SYSTEM

\begin{tabular}{|c|c|c|}
\hline $\begin{array}{l}\text { Primary } \\
\text { index }\end{array}$ & $\begin{array}{l}\text { Secondary } \\
\text { index }\end{array}$ & Description \\
\hline \multirow{2}{*}{ Safety } & Safety level & $\begin{array}{l}\text { Cloud service safety level as issued by } \\
\text { supervisory organ }\end{array}$ \\
\hline & $\begin{array}{l}\text { Authorized } \\
\text { access }\end{array}$ & $\begin{array}{l}\text { Service authority as offered to users } \\
\text { according to SLA }\end{array}$ \\
\hline Extensibility & Extensibility & $\begin{array}{l}\text { Capability in satisfying users' demands } \\
\text { for resources }\end{array}$ \\
\hline \multirow{2}{*}{ Reliability } & Accuracy & $\begin{array}{l}\text { Probability of successful satisfaction to } \\
\text { users' demands by cloud service }\end{array}$ \\
\hline & Robustness & $\begin{array}{l}\text { Capability in maintaining normal } \\
\text { operation in case of abnormality }\end{array}$ \\
\hline \multirow[b]{2}{*}{ Performance } & $\begin{array}{l}\text { Throughput } \\
\text { rate }\end{array}$ & $\begin{array}{l}\text { Total number of cloud services in the } \\
\text { unit time }\end{array}$ \\
\hline & $\begin{array}{l}\text { Data } \\
\text { management } \\
\text { capability } \\
\end{array}$ & $\begin{array}{l}\text { Users' recognition of cloud service after } \\
\text { use, which is normally defined according } \\
\text { to sequencing }\end{array}$ \\
\hline \multirow[t]{2}{*}{ Serviceability } & $\begin{array}{l}\text { Mean time } \\
\text { between } \\
\text { failure }\end{array}$ & $\begin{array}{l}\text { Normal operation time between two } \\
\text { adjacent failures }\end{array}$ \\
\hline & $\begin{array}{l}\text { Response } \\
\text { time }\end{array}$ & $\begin{array}{l}\text { Duration from issuance of service } \\
\text { request from users to service acquisition }\end{array}$ \\
\hline $\begin{array}{l}\text { Resources } \\
\text { utilization rate }\end{array}$ & $\begin{array}{l}\text { Resources } \\
\text { utilization } \\
\text { rate }\end{array}$ & $\begin{array}{l}\text { Proportion of resources as actually } \\
\text { acquired by consumers in preliminarily } \\
\text { customized ones }\end{array}$ \\
\hline \multirow{2}{*}{ Cost } & $\begin{array}{l}\text { Price of } \\
\text { cloud service } \\
\text { resources }\end{array}$ & $\begin{array}{l}\text { Remunerations as requested by service } \\
\text { provider for unit resource }\end{array}$ \\
\hline & Penalties & $\begin{array}{l}\text { Compensations payable to users in case } \\
\text { of breach of contract on the part of } \\
\text { service provider }\end{array}$ \\
\hline
\end{tabular}

SD Software was used for grading in multiple comparison input mode in combination with reclaimed questionnaires to eventually obtain weight of primary and secondary indexes respectively (See Table 3 and Table 4).

Viewing from aforesaid table, it can be seen that users attach highest importance to the safety among primary evaluation indexes for cloud service quality. Such weight value of 0.379464 is obviously higher than 0.177272 for reliability that comes to the second place. It is followed by serviceability, performance, cost, extensibility and resources utilization rate in sequence.

According to analysis, Secondary indexes are sequenced as follows in terms of their importance: resources utilization rate, response time, authorized access, mean time between failure, data management capability, safety level, throughput 
rate, accuracy, robustness, extensibility, cloud service resource price and penalties. In view of values, resources utilization rate, authorized access and means time between failure come to the top in terms of importance among secondarv indexes.

TABLE II. INFLUENCING RELATIONSHIP BETWEEN EACH SECONDARY INDEX FOR CLOUD SERVICE QUALITY

\begin{tabular}{|l|l|l|l|l|l|l|l|l|l|l|l|l|}
\hline C1 & C1 & C2 & C3 & C4 & C5 & C6 & C7 & C8 & C9 & C10 & C11 & C12 \\
\hline C2 & & $/$ & 1 & 1 & 1 & & 1 & & 1 & & & \\
\hline C3 & & & $/$ & & & & 1 & & & 1 & & \\
\hline C4 & & & $/$ & & 1 & 1 & 1 & 1 & & & \\
\hline C5 & & & & $/$ & 1 & 1 & 1 & 1 & & & \\
\hline C6 & & & & & $/$ & & 1 & 1 & 1 & & \\
\hline C7 & & & & & 1 & $/$ & 1 & 1 & & & \\
\hline C8 & & & & & & & $/$ & 1 & & & \\
\hline C9 & & & & & & & & $/$ & 1 & & \\
\hline C10 & & & & & & & & & $/$ & & \\
\hline C11 & & & & & & & & & & $/$ & \\
\hline C12 & & & & & & & & & & & $/$ \\
\hline
\end{tabular}

C1:Safety level; C2: Authorized access; C3:Extensibility; C4: Accuracy; C5: Robustness; C6: Throughput rate; C7:Data management capability; C8: Mean time between failure; C9:Response time; C10: Resources utilization rate; C11: Price of cloud service resources; C12: Penalties

TABLE III. WEIGHT SEQUENCING OF PRIMARY INDEXES

\begin{tabular}{|c|c|c|c|c|c|c|c|c|c|}
\hline & B1 & B2 & B3 & B4 & B5 & B6 & B7 & $\begin{array}{l}\text { Weight } \\
\text { Value }\end{array}$ & $\begin{array}{l}\text { Importance } \\
\text { Sequencing }\end{array}$ \\
\hline B1 & 1 & 6 & 3 & 4 & 5 & 7 & 3 & 0.379464 & 1 \\
\hline B2 & & 1 & $1 / 5$ & $1 / 4$ & $1 / 2$ & 2 & $1 / 2$ & 0.048823 & 6 \\
\hline B3 & & & 1 & 2 & 2 & 3 & 2 & 0.177272 & 2 \\
\hline B4 & & & & 1 & 2 & 3 & $1 / 2$ & 0.121917 & 4 \\
\hline B5 & & & & & 1 & 5 & 4 & 0.135068 & 3 \\
\hline B6 & & & & & & 1 & 1 & 0.044013 & 7 \\
\hline B7 & & & & & & & 1 & 0.093443 & 5 \\
\hline
\end{tabular}

It should be mentioned that resources utilization rate has the lowest priority among primary indexes (coming to the 7th place); however, it dramatically comes to the first place in terms of importance among secondary indexes. This is due to the fact that there are three factors affecting the resources utilization rate on the same hierarchy according to survey of relationship between each secondary index, namely extensibility, throughput rate and response time; whereas response time in affected by accuracy, authorized access, robustness, throughput rate, data management capability and mean time between failure. In other words, 6 among 7 primary indexes have direct or indirect impact on resources utilization rate. Such a result is exactly incurred by complicated network relationship between each secondary index. This is just the advantage of ANP method used to analyze and process complicated situations.

TABLE IV. WEIGHT SEQUENCING OF SECONDARY INDEXES

\begin{tabular}{|c|c|c|c|c|}
\hline $\begin{array}{c}\text { Primary } \\
\text { index }\end{array}$ & $\begin{array}{c}\text { Weight } \\
\text { Value }\end{array}$ & $\begin{array}{c}\text { Secondary } \\
\text { index }\end{array}$ & Weight & Sequencing \\
\hline \multirow{2}{*}{ B1 } & \multirow{2}{*}{0.379464} & C1 & 0.078299 & 6 \\
\cline { 3 - 5 } & & C2 & 0.091349 & 3 \\
\hline B2 & 0.048823 & C3 & 0.019501 & 10 \\
\hline \multirow{2}{*}{ B3 } & \multirow{2}{*}{0.177272} & C4 & 0.054446 & 8 \\
\cline { 3 - 5 } & & C5 & 0.054036 & 9 \\
\hline B4 & 0.121917 & C6 & 0.059102 & 7 \\
\cline { 3 - 5 } & & C7 & 0.079644 & 5 \\
\hline B5 & \multirow{2}{*}{0.135068} & C8 & 0.090083 & 4 \\
\hline & & C9 & 0.101209 & 2 \\
\hline B6 & 0.044013 & C10 & 0.125601 & 1 \\
\hline \multirow{2}{*}{ B7 } & \multirow{2}{*}{0.093443} & C11 & 0.011642 & 11 \\
\cline { 3 - 5 } & & C12 & 0.003881 & 12 \\
\hline
\end{tabular}

\section{CONCLUSION}

The thesis has creatively proposed secondary evaluation index system for cloud service quality for the first time in the industry, and performed sequencing and analysis of weight for the index system. Weight sequencing of primary indexes has been basically recognized by experts based on feedback of analysis results; however, they have different opinions on sequencing of secondary indexes. According to analysis, this is due to the lack of profound cognition of cloud computation among interviewees. They have a more precise cognition of primary indexes as compared with 11 secondary indexes as further divided. This has directly resulted in poor quality of reclaimed questionnaires and unsatisfactory analysis results.

Generally speaking, the thesis has constructed two index systems for evaluation of cloud services, considered influencing relationship between each index, specified ANP method for establishment of index system model, and defined weight of each index in the model. It has also provided sequencing of all indexes in terms of their importance, and proposed a novel conception on evaluation of cloud service quality. This has promoted regulated development of cloud computation to some extent. 


\section{REFERENCES}

[1] Deng Zhonghua, Wang Xuansheng and Li Zhifang, Study on Evaluation Indexes for Cloud Service for Information Resources, [J]. Library and Information, 2012(4): 12-15

[2] Xu Fengju and Dai Lina, Application of ANP in Evaluation of Performance of R\&D Personnel of Hi-tech Enterprises, [J], Finance and Accounting Monthly, 2008(10): 33-35

[3] Liu Lu, Zhou Keji and Liang Yan, Cognition of Cloud Service Quality Management and Study, [J], Designing Techniques of Posts and Telecommunications, 2012(7): 1-4

[4] Chen Zhu and Li Hao, Study of Measuring Method for Cloud Service Quality Based on Cloud Bank, [J], Journal of Guangxi Teachers Education University, 2013(7): 31-34

[5] Huang Yun, QoS Based Cloud Service Evaluation Model and Application Study, [D], Zhejiang Gongshang University, 2013(1) 